\title{
Fuzzy batch controller for granular materials
}

\author{
Nikolaj Zamyatin ${ }^{1, *}$, Gennadij Smirnov ${ }^{1}$, Yuri Fedorchuk ${ }^{2}$, and Olga Rusina ${ }^{2}$ \\ ${ }^{1}$ Tomsk State University of Control Systems and Radioelectronics, 634050 Tomsk, Russia \\ ${ }^{2}$ National Research Tomsk Polytechnic University, 634050 Tomsk, Russia
}

\begin{abstract}
The paper focuses on batch control of granular materials in production of building materials from fluorine anhydrite. Batching equipment is intended for smooth operation and timely feeding of supply hoppers at a required level. Level sensors and a controller of an asynchronous screw drive motor are used to control filling of the hopper with industrial anhydrite binders. The controller generates a required frequency and ensures required productivity of a feed conveyor. Mamdanitype fuzzy inference is proposed for controlling the speed of the screw that feeds mixture components. As related to production of building materials based on fluoride anhydrite, this method is used for the first time. A fuzzy controller is proven to be effective in controlling the filling level of the supply hopper. In addition, the authors determined optimal parameters of the batching process to ensure smooth operation and production of fluorine anhydrite materials of specified properties that can compete with gypsumbased products.
\end{abstract}

\section{Introduction}

To ensure the smooth production of building products based on fluorine anhydrite, it is necessary to monitor continuous filling of supply hoppers with a raw material - industrial anhydrite binder. This is essential for timely batching at a specified, carefully adjusted ratio of initial components and, therefore, production of anhydrite-based building products with required strength and waterproof characteristics. Industrial anhydrite binder is produced from fluorine anhydrite, a waste product of chemical industry, which can replace natural gypsum in the traditional building materials industry [1-7].

Batch control of granular materials with a fuzzy controller is proposed for production based on fluorine anhydrite. This solution can be used under conditions of incomplete information where smoother switching with more accurate timing is required. Therefore, the aim of our study is to analyze the possibility of using a controller based on principles of fuzzy logic to maintain a required level of industrial anhydrite binder in a supply hopper.

Fuzzy controllers based on fuzzy inference systems $[8,9]$ are able to produce control actions, just like a human operator who makes decisions and controls stages of the production process. Researchers proposed different applications of the fuzzy controller in production processes, for example, maintaining constant temperature, water level in a tank, etc. [10-12]. For the first time, the fuzzy controller is proposed for the production of

* Corresponding author: zamnv47@gmail.com 
building materials based on fluorine anhydrite. It can be used as an element of the automatic level control system that controls filling of supply hoppers with industrial anhydrite binder.

\section{Research Methods}

Different studies and system modeling in the field of artificial intelligence are often founded on principles of fuzzy logic and the fuzzy-set theory. Fuzzy control processes are modeled mostly in the popular MATLAB environment using a special Fuzzy Logic Toolbox package [13-14].

Fuzzy inference processes are modeled on the basis of an if-then rule base and membership functions of linguistic terms.

Modeling can be performed under the following conditions:

- there is at least one rule for the relevant linguistic terms of the output variable;

- any term of the input variable contains at least one rule, in which it is a premise.

This paper considers fuzzy inference based on the Mamdani mechanism, the most common inference approach in fuzzy systems.

A supply hopper is used as a fuzzy controlled element.

\section{Construction of the Fuzzy Controller}

A frequency converter of the signal transmitted to the screw drive motor is used as a controlling element in the supply hopper. A controller of the asynchronous screw drive motor is designed to monitor filling of the hopper with industrial anhydrite binder. The controller generates a required frequency, thereby ensuring required productivity of the feed conveyor.

Relying on the accumulated experience of studying production processes based on fluorine anhydrite and our own studies [15-18], we have established that levels of the supply hopper depend on its productivity for fluorine anhydrite $(G)$, while the normal level of the supply hopper, Level $_{\text {norm, }}$, is $\mathrm{G}$ x 8 hours +0.5 hours of margin; the maximum level, Level $_{\max }$, is $\mathrm{G} \times 8+1.0 \times \mathrm{G}=9 \times \mathrm{x}$; the minimum level, Level ${ }_{\min }$, is $1.0 \times \mathrm{G}$.

The knowledge base of the fuzzy controller includes the following rules:

1. If the level of industrial anhydrite binder in the supply hopper is below the minimum, the controller of the asynchronous screw drive motor generates $60 \mathrm{~Hz}$ (the maximum productivity of the feed conveyor is $100 \%$ );

2. If the level of industrial anhydrite binder in the supply hopper is above the minimum but below the normal level, the controller generates $54 \mathrm{~Hz}$ (the productivity of the feed conveyor is $90 \%$ );

3. If the level of industrial anhydrite binder in the supply hopper is normal, the controller generates $30 \mathrm{~Hz}$ (the productivity of the feed conveyor is $50 \%$ );

4. If the level of industrial anhydrite binder in the supply hopper is above the normal level but below the maximum, the controller generates $6 \mathrm{~Hz}$ (the productivity of the feed conveyor is $10 \%$ );

5. If the level of industrial anhydrite binder in the supply hopper achieves the critical level but is still below the maximum, the controller generates $0 \mathrm{~Hz}$ (the productivity of the feed conveyor is $0 \%$ );

We take $8.5 \mathrm{xG}$ as the normal level; $9 \mathrm{xG}$ as the maximum level, and $1.0 \mathrm{xG}$ as the minimum level, where $G$ is the productivity of the feed conveyor. Consumption of industrial anhydrite is assumed to be constant. 
We choose frequency and productivity as input variables of the fuzzy inference system, and the fuzzy linguistic variable "level" as an output variable.

The range of input variables (Range and Display Range) is from $1 \mathrm{~Hz}$ to $60 \mathrm{~Hz}$ for the variable "frequency" and from $1 \%$ to $100 \%$ for the variable "productivity".

Figure 1 shows a membership function editor after making changes for the input frequency variable. A membership function editor for the input variable "productivity" has the similar form.

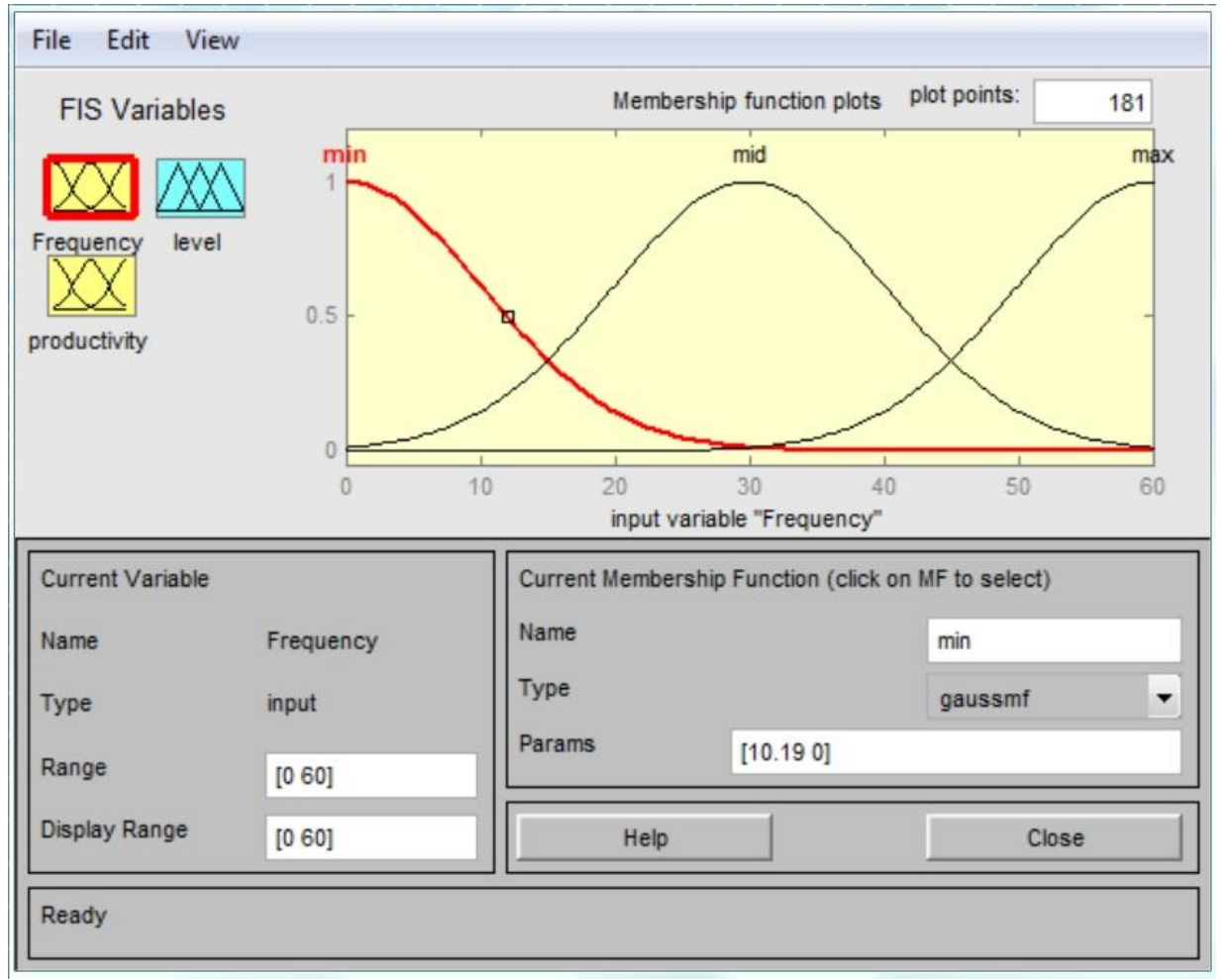

Fig. 1. Membership functions of the input signal "frequency".

We also change the names of terms for the output variable "level". Then we choose a membership function of triangular type. We take values [ $\left.\begin{array}{llll}0 & 0.02644 & 1\end{array}\right]$ for the term "productivity"; [ $\left.\begin{array}{lll}1 & 3.75 & 8.3\end{array}\right]$ for the term "min"; [ 8.3 8.4 8.5] for the term "norm", [8.3 8.5 9.33] for the term "more min"; and [ $\left.\begin{array}{lll}8.6 & 8.82 & 8.9\end{array}\right]$ for the term "more norm". The membership function editor after making changes for the output variable "level" is shown in Figure 2.

The fuzzy inference rules for the fuzzy system under development are generated in the rule editor of the Fuzzy Logic Toolbox package. 


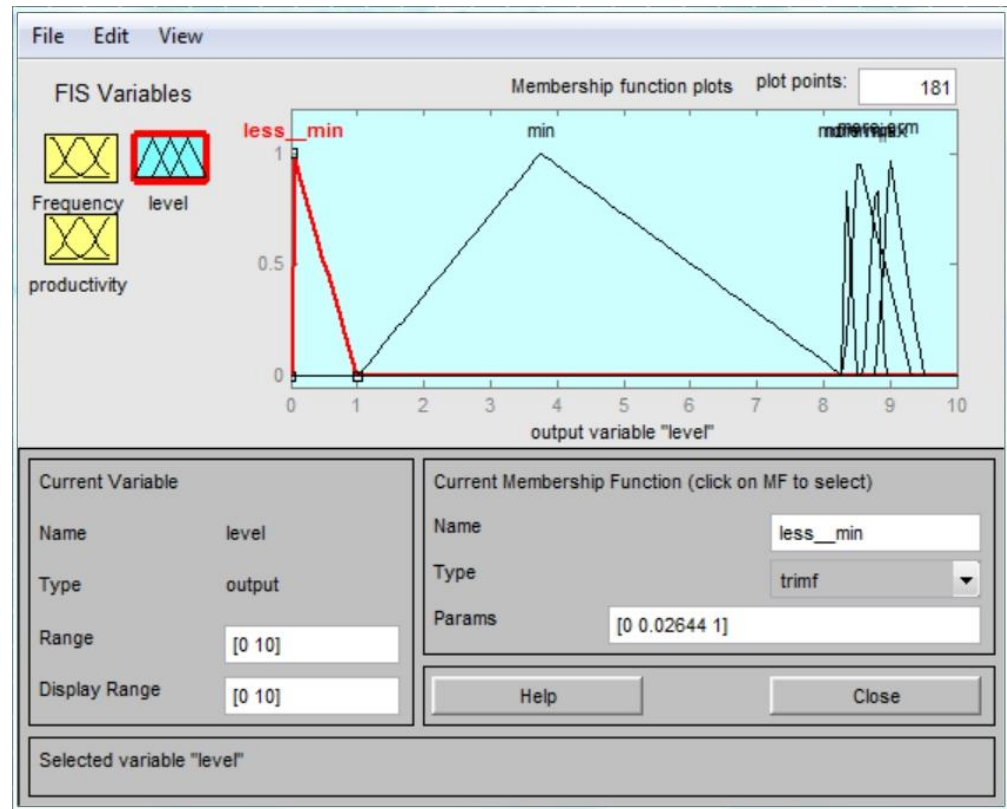

Fig. 2. Membership functions of the output signal "level".

Figure 3 presents a window of the rule viewer, which shows that average values from the allowable range (values [ 30 50] in the Input field) are proposed as default values for the input variables. This means that the controller produces $30 \%$ when the productivity of the feed conveyor is $50 \%$. These values of the input variables correspond to $8.52 \mathrm{xG}$ level of the supply hopper, which is the normal filling level of the hopper. Therefore, the model is valid (Fig. 3).

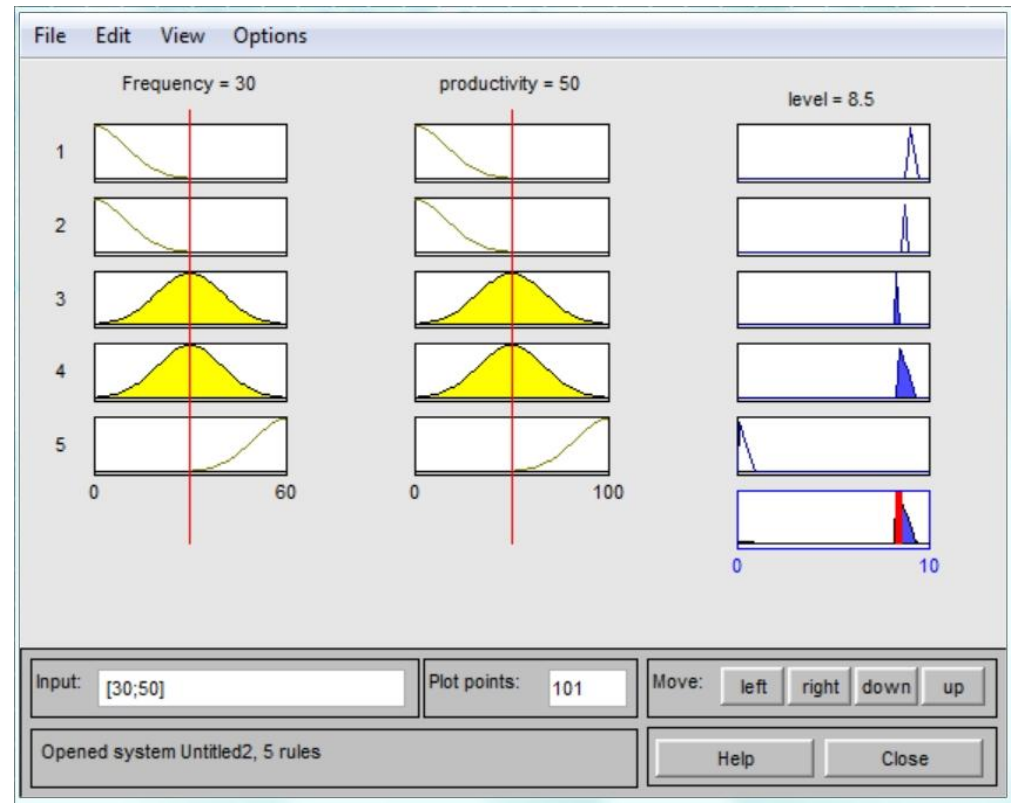

Fig. 3. Interface of the software. 


\section{Results}

The logical inference algorithm usually consists of the following stages: fuzzification, fuzzy inference, composition and defuzzification (Figure 4).

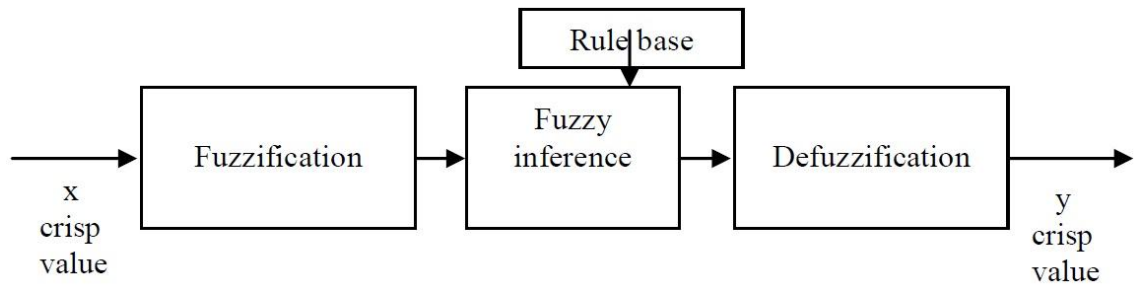

Fig. 4. Fuzzy logic inference system.

Fuzzification is conversion of $\mathrm{x}$ values into fuzzy format. Defuzzification is a procedure reverse to fuzzification.

Each fuzzy inference algorithm has its own set of logical operations and rules, as well as its own type of defuzzification method. Fuzzy inference models of Sugeno, Tsukamoto, Larsen and Mamdani are known.

Functioning of fuzzy logic systems is based on a single principle: readings from measuring devices are fuzzificated, processed, defuzzificated and transmitted to actuators in the form of usual signals.

This paper considers a fuzzy inference based on the Mamdani mechanism. The feature of this mechanism is that the minimax composition of fuzzy sets is used in modeling.

For final analysis of the developed fuzzy model, we constructed a fuzzy inference surface using a fuzzy inference surface viewer (Fig. 5). This viewer allows us to analyze the adequacy of the constructed fuzzy model and to assess how a change in one of the input linguistic variables affects the output variable. As can be seen from the figure, the response surface is adequate and sensitive to input effects.

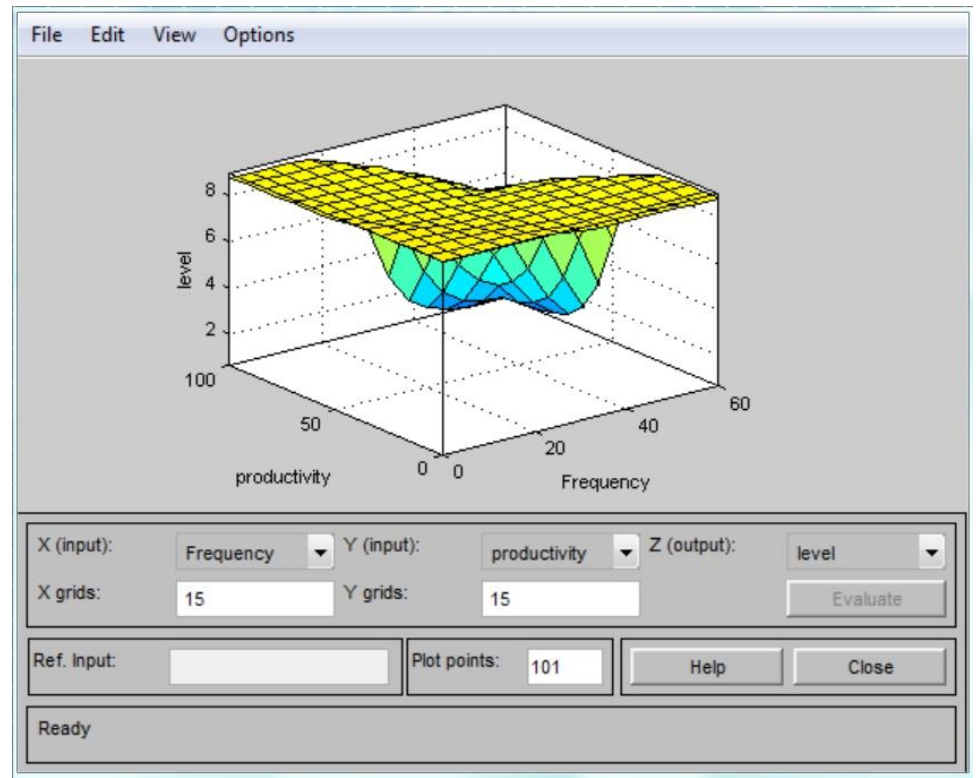

Fig. 5. Interface of the fuzzy inference surface viewer for the developed fuzzy model. 
Thus, it is possible to determine optimal parameters of production processes in the building materials industry through modeling of the fuzzy controller, without additional laboratory tests and experiments.

\section{Conclusion}

Thus, it was found that the proposed modeling of the fuzzy controller could be successfully applied by producers of building materials from fluorine anhydrite waste. Based on chosen input linguistic parameters, frequency and productivity, we created rules to generate a fuzzy linguistic variable "level", and determined their values and relationships. Using these results, we tried out control actions to control the required filling level of the supply hopper at an existing production facility where fluorine anhydrite was used.

This approach minimizes the so-called "human factor" when making decisions about batching of industrial anhydrite binder, reduces the time of production operations and, therefore, contributes to bringing an enterprise to a new, modern level where it can compete with enterprises that use natural gypsum.

It is reasonable to further increase the accuracy of filling and batching control in relation to industrial anhydrite binder by improving the fuzzy inference rule base. The calculations performed in this study suggest that this kind of modeling is applicable to other stages of production based on fluorine anhydrite, such as batching of initial components of the building fluorine anhydrite mixture - ash and slag waste, water and improvers.

\section{References}

1. U. Kuhlmann, DE Patent 3023666 (1981)

2. H. Scsmidt, G. Fietsch, R. Grohmann, H-J. Grun, P. Pfutzner, FR Patent 2495131 (1982)

3. T. Gaedt, H. Grassl, M. Winklbauer, O. Mazanec, US Patent 2017022108 (2017)

4. D. Hums, K. Lippe, DE Patent 19619263 (1997)

5. K. Harr, M. Tax, G. Bolte, I. Unsin, DE Patent 4313148 (1994)

6. E. Stave, E. A. BurKard, R. Finkelstein, AU Patent 2124799 (1999)

7. P.A. Carlucci, FR Patent 2727675 (1996)

8. M.V. Krivenkov, S. R. Zalyaleev, A. N. Pakhomov, Optimizacija raboty jelektrotehnicheskih sistem [Optimization of electrical systems], 315 (Krasnoyarsk, 2006)

9. Y. Peng, J. Luo, J. Zhuang, C. Wu, Proceedings of the IEEE International Conference on Automation and Logistics (Qingdao, China September 2008), 896-901

10. D. Wu, F. Karray, I. Song, Proceedings of the IEEE Conference on Control Applications, 3134-39 (2005)

11. G. Zhiqiang, T.A. Trautzsch, J.G. Dawson, IEEE Transactions on Industry Applications, 38(2), 414 - 424 (2002)

12. Z. Zhi, H. Li-Sheng, Annals of Nuclear Energy, 45, 94-105 (2012)

13. T. Hung, M. Sugeno, R. Tong, R.R. Yager, Theoretical aspects of fuzzy control (John Wiley and Sons Inc., New York, 1995)

14. J. Yen, R. Langari, Fuzzy logic: intelligence, control, and information (Prentice Hall, New Jersey, 1998)

15. Yu.M. Fedorchuk, Scientific basis and methods for environmental impact reduction in hydrogen fluoride production areas, doctoral thesis (Tomsk, 2004)

16. T.S. Tsygankova, Development of methods for reducing environmental impact of hydrogen fluoride production sites, PhD thesis (Tomsk, 2009) 
17. O.V. Volkova, Finishing dry building mixes based on fluoride acid binders, $\mathrm{PhD}$ thesis (Tomsk, 2015)

18. L.A. Anikanova, Fluoride acid composites for low-rise buildings, $\mathrm{PhD}$ thesis (Tomsk, 1997) 